\title{
IdeAs
}

Idées d'Amériques

15 | 2020

Eau et gestion de l'eau dans les Amériques

\section{Segurança hídrica e mudanças climáticas no Brasil: uma entrevista cruzada com Jerson Kelman e João Paulo Capobianco.}

Livia Kalil e Guilherme B. Checco

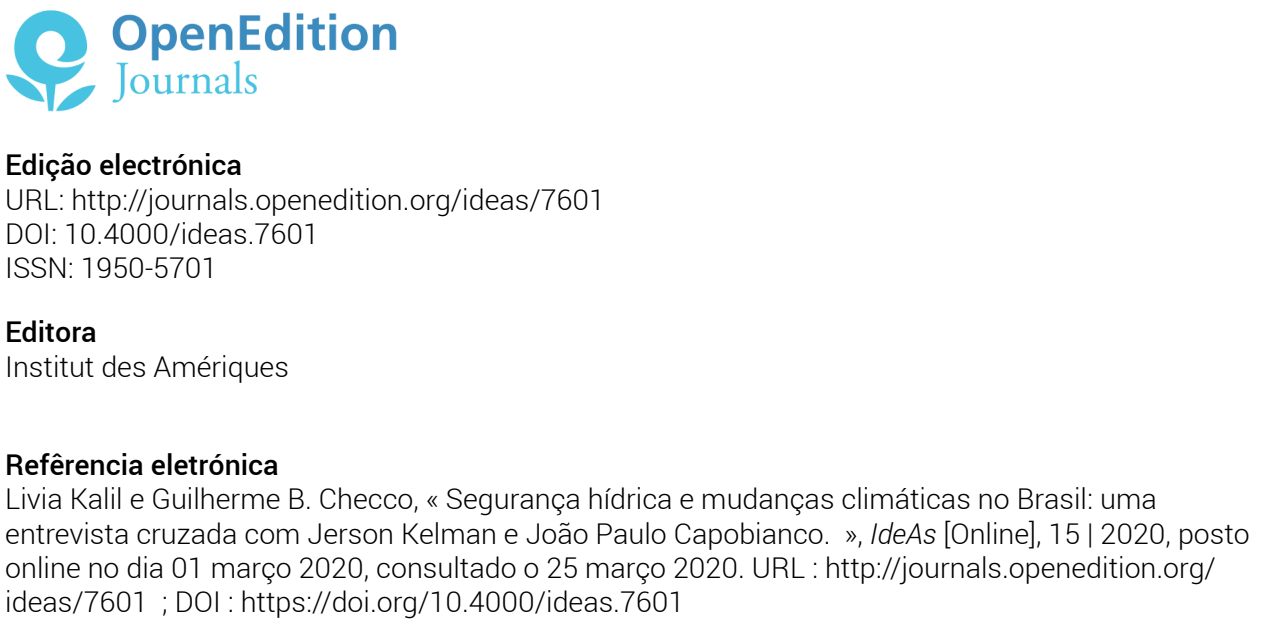

Este documento foi criado de forma automática no dia 25 março 2020

\section{$(1) \Theta$}

IdeAs - Idées d'Amériques est mis à disposition selon les termes de la licence Creative Commons Attribution - Pas d'Utilisation Commerciale - Pas de Modification 4.0 International. 
Segurança hídrica e mudanças climáticas no Brasil: uma entrevista cruzada com Jerson Kelman e João Paulo Capobianco. Livia Kalil e Guilherme B. Checco

Jerson Kelman

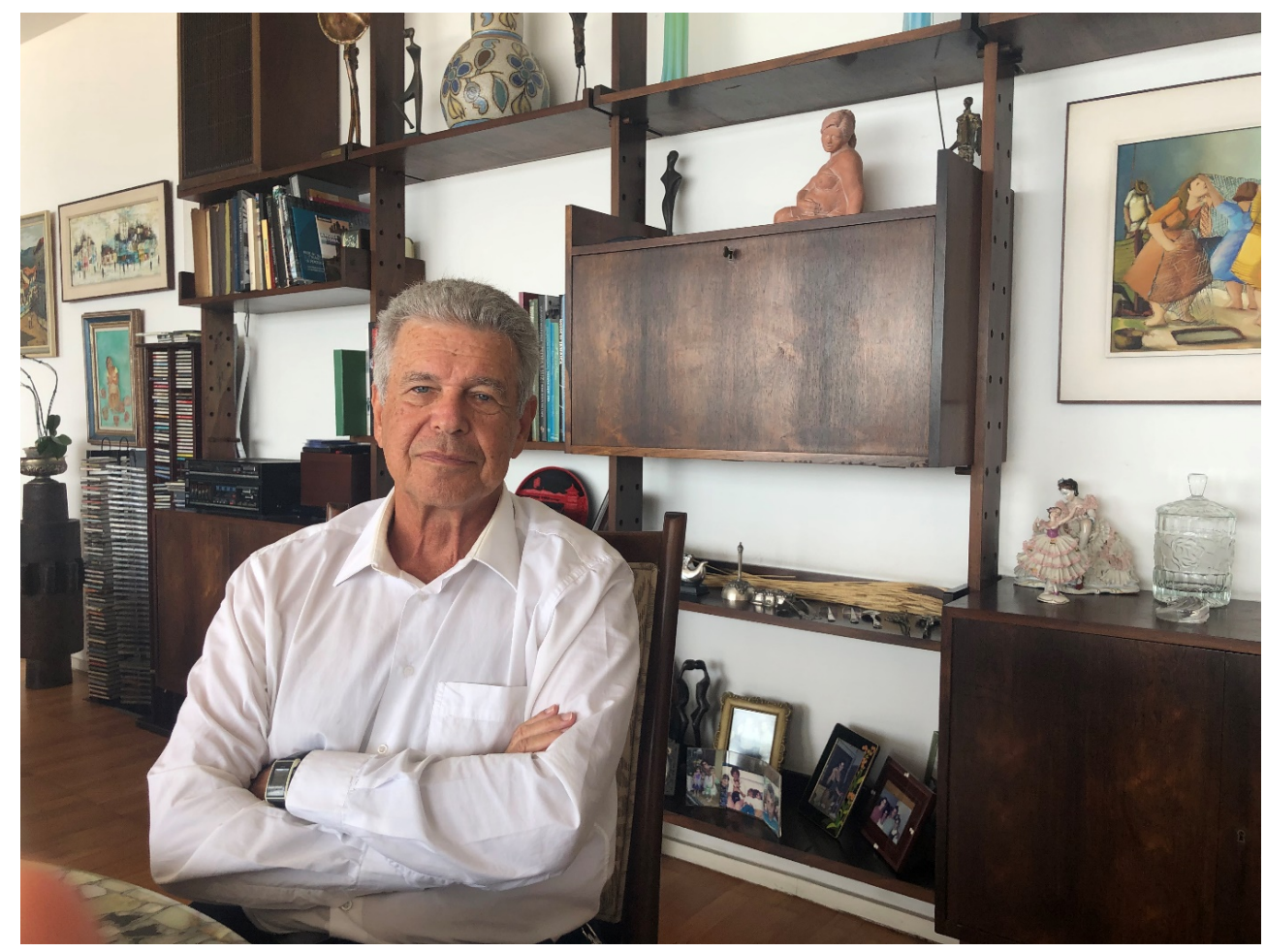

(c) Livia Kalil 
João Paulo Capobianco

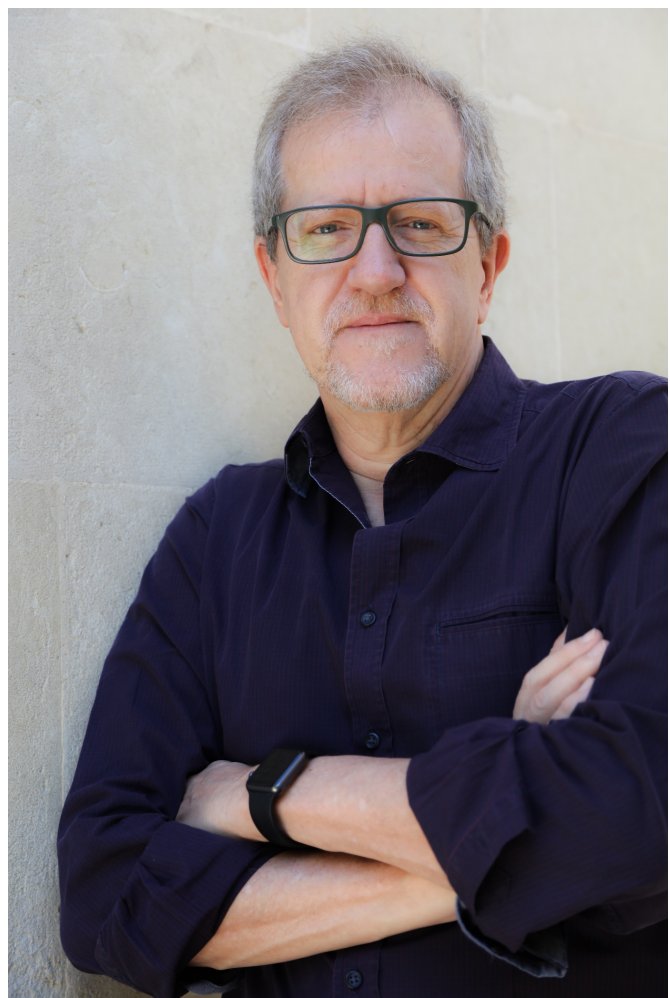

(C) Luciana Capobianco

O conhecimento científico é categórico ao afirmar que um dos principais impactos das mudanças climáticas é no ciclo hidrológico (IPCC, 2014 e 2018). O Brasil é um país que desempenha um papel estratégico nesta questão. Além de estar entre os maiores emissores de gases de efeito estufa do mundo (mais precisamente o $7^{\circ}$ ), tendo a maior e mais biodiversa floresta tropical, é também o país com a maior reserva de água doce do mundo, respondendo por $12 \%$ do total. Entretanto, os impactos das mudanças climáticas e dos eventos hidrológicos extremos já fazem parte da realidade brasileira (Marengo, 2008). Somente em 2018, um milhão de brasileiros foram afetados pelas inundações e quase 43 milhões pela seca (ANA, 2019). Compreender tal desafio é uma tarefa que requer uma visão estratégica e multidisciplinar.

Assim, decidimos entrevistar dois especialistas nesta área, com trajetórias dedicadas ao Brasil, em particular a esta questão. Jerson Kelman e João Paulo Capobianco já trabalharam juntos no Ministério do Meio Ambiente. No entanto, mantiveram as suas ideias e particularidades, bem como as suas áreas políticas específicas. Nesta entrevista cruzada, os especialistas fazem um diagnóstico profundo da situação atual e propõem caminhos para a gestão da água no Brasil frente às mudanças climáticas com uma complementaridade interessante. Kelman é engenheiro de formação, professor da Universidade Federal do Rio de Janeiro (UFRJ) e ex-diretor e presidente da Agência Nacional de Águas (ANA). E Capobianco, biólogo, ambientalista, responsável pela fundação de várias organizações sociais como a Fundação SOS Mata Atlântica e o Instituto Socioambiental (ISA) e ex-Secretário Executivo do Ministério do Meio Ambiente. 
LIVIA KALIL E GUILHeRMe B. CHeCco (L.K., G.B.): Você poderia dar uma explicação geral sobre a governança das águas no Brasil?

Jerson Kelman (J.K.): Quando se fala em água, é necessário fazer uma distinção de in ício. Uma coisa é a gestão de água doce em estado "bruto", água dos rios, dos reservat órios. E outra é o serviço de captação e tratamento de água, e coleta e tratamento de esgoto, ou seja, serviço de saneamento. Às vezes essas duas coisas são misturadas.

Falando sobre o primeiro, sobre a gestão das águas enquanto recurso natural, no Brasil, segundo a Constituição Federal de 1988 as águas que fazem fronteira estaduais ou com outros países são de domínio da União. A CF é um pouco vaga sobre o que seriam as demais águas. Essa dubiedade foi preenchida com o prolongamento de um entendimento que havia desde Constituições anteriores, que os rios que desembocassem em um mesmo estado seriam de responsabilidade estadual.

Ao meu ver, o Brasil infelizmente não adotou um sistema único de atribuição de responsabilidade governamental pela água. Semelhante ao que ocorre na França, em um Estado que não é uma federação. Então, na França, certamente é mais fácil administrar o recurso natural água, do que é no Brasil. O Brasil sofre de uma complicação a esse respeito, que afeta os países federados, como é o caso dos Estados Unidos e da Austrália. A dificuldade é que quando você tem a titularidade, ou seja, a responsabilidade pela gestão do recurso natural dividido na mesma bacia hidrográfica entre diferentes entidades, isso cria uma dificuldade técnica e administrativa. Sabemos que uma gota de água numa bacia hidrográfica não sabe onde caiu, e que, segundo a interpretação da Constituição, estará sob a administração do estado A em um momento, depois sob o controle do estado B em outro momento, e depois sob a responsabilidade do governo federal. Muitas autoridades são respons áveis pelo mesmo recurso. A unidade de gestão deve ser a da bacia hidrográfica, porque o equilíbrio entre a oferta e demanda, em termos de quantidade e qualidade, requer a consideração de todos os usos na bacia - uma decisão tomada num afluente que irá afetar a disponibilidade de água a jusante. Portanto, esta dupla dominialidade [entre a União e os diferentes Estados] é muito difícil de implementar.

João Paulo Capobianco (JPC): Do ponto de vista teórico, a concepção da governança da água no Brasil, especialmente da política de saneamento básico, é bastante avan çada e em teoria deveria, se bem aplicada, ser bastante eficaz. Ela pressupõe uma exig ência de planejamento, com processos participativos, articulando os principais atores envolvidos na questão do uso da água, com um papel importante para os municípios que são os responsáveis constitucionais pela gestão da água. Ou seja, em tese é um instrumento que conteria os elementos fundamentais para uma gestão negociada e democrática e, portanto, com chances de gerar bons resultados. Tanto na manutenção do fundamental, que é a produção natural de água com a qualidade e quantidade necessárias, como no uso socialmente justo, equilibrado e ecologicamente responsável de um bem finito como é a água. Ou seja, os instrumentos são bastante avançados, mas o que se vê no entanto é que eles não geram esses resultados.

L.K., G.B.: Quais os principais desafios da gestão dos recursos hídricos no país?

J.K. O primeiro desafio é comum ao que aconteceu em todos os países desenvolvidos que já resolveram este problema: a poluição. Ou seja, o desafio de fornecer infraestrutura para a coleta e tratamento de águas residuais. A França enfrentou este problema na década de 1960 através da criação da taxa de poluição e das agências de 
bacia. Isto foi feito através da tributação dos cidadãos franceses, que começaram a pagar este imposto nas suas contas de água. $\mathrm{Na}$ minha visão distante do que aconteceu na França, isso significou que as agências da bacia desenvolveram um grande poder econômico porque foram capazes de levantar fundos significativos. Assim, foi o próprio cidadão francês que permitiu à França, com a taxa, pôr fim à poluição dos rios e riachos. O Brasil está passando por um período semelhante ao que a França passou. No Brasil não criamos esse sinal econômico para os consumidores e não criamos essa "massa" de recursos financeiros capazes de fazer todos os investimentos necessários possíveis.

O segundo desafio é uma questão quantitativa, especialmente no Nordeste, mas não exclusivamente. Se compararmos a precipitação média no Nordeste do Brasil e na França, elas são semelhantes, cerca de $600 \mathrm{~mm}$ por ano. Então porque é que o regime hidrológico é diferente? Porque em geral, no Nordeste, os solos são rasos, de modo que a chuva, quando cai, rapidamente satura o solo e a água começa a drenar superficialmente, formando rios intermitentes. E esta água, se não for armazenada, flui para o mar. Grande parte do Nordeste é semi-árido. A única forma de resolver este problema é, portanto, a implementação de obras hidráulicas e boas práticas de conservação de água.

Problema número 3: Não há razão para o Brasil não imitar o que está sendo feito nos Estados Unidos. Lá, a produção de grãos do Meio Oeste flui para o resto do mundo ao longo do rio Mississippi. E isso reduz os custos de transporte. No Brasil usamos a rodovia, que é muito cara. Assim, o uso dos rios Amazônicos para transportar a produção do centro do Brasil - hoje uma grande região produtora de grãos - e també m para gerar eletricidade são duas questões que não são bem consideradas. Há quase uma histeria coletiva quando se fala em desenvolver obras nos rios amazônicos, nacional e internacionalmente. Isto coloca muita ênfase nas consequências locais de obras em um rio amazônico, com quase sempre más opiniões. Há muito interesse nisso e pouco interesse nos efeitos mais globais. Tem de ser analisado caso a caso. Em alguns casos, parece-me lógico não demonizar o trabalho em rios amazônicos. Este é um grande desafio para o desenvolvimento do centro-oeste e da região amazônica.

J.P.C.: Hoje, a gestão da água no Brasil é extremamente frágil, o acesso não é universalizado. Isto é inaceitável e obviamente revela uma lacuna entre o que a lei prevê e os instrumentos que ela define na realidade. $O$ tratamento e o saneamento também não são resolvidos.

Isto é uma contradição, porque estamos falando da contaminação dos recursos hídricos onde eles são mais necessários, o que requer cada vez mais sofisticação no tratamento, como investimentos para buscar água em lugares mais distantes onde ela tem uma qualidade mais adequada para o consumo.

Estamos, portanto, assistindo a uma situação totalmente contraditória, porque temos um quadro jurídico muito avançado, mas uma realidade muito retrógrada. Estamos diante de uma perda crescente de área de superfície das fontes de água causada pela degradação do território ou pela contaminação resultante.

L.K., G.B.: Existe uma relação entre mudanças climáticas e gestão hídrica? Qual a relevância do impacto das mudanças climáticas na gestão das águas? As políticas 
públicas brasileiras relacionadas à gestão hídrica incorporam de maneira devida o componente climático?

J.K.: Existem diversos elos entre as mudanças climáticas e a água. Em primeiro lugar, a temperatura está aumentando, a evapotranspiração está aumentando, e por isso, as práticas agrícolas exigirão mais água. O consumo humano de água também vai aumentar, porque em geral o consumo cresce junto com o aumento da temperatura. Também é preciso levar em conta que os regimes hidrológicos estão mudando. A segunda variável é a pluviosidade. Uma mudança significativa foi observada no caso do Brasil em relação aos regimes pluviométricos e fluviais. Dois exemplos: no caso do Rio São Francisco, 19 dos últimos 20 anos tiveram uma vazão média inferior à média de longo prazo. De um ponto de vista probabilístico, isto parece totalmente improvável. No entanto, algo está acontecendo. A chuva de fato diminuiu, então há de fato uma alteração da precipitação na bacia do rio, mas isso não explica completamente a mudança na vazão. Então parte é por conta na alteração de precipitação e parte por mudança do uso do solo, essencialmente o aumento da agricultura irrigada. Quando você aumenta a irrigação, você aumenta a transpiração, assim menos água chega ao rio. Então, neste exemplo, há nitidamente uma mudança de regime hidrológico que possivelmente possa ser relacionado de forma parcial com a diminuição da precipitação, que talvez esteja relacionado com mudança climática. No sul do Brasil, na bacia do Rio Paraná, a saída deste rio do Brasil, quando ele entra no território argentino, se dá na hidrelétrica de Itaipú. Na bacia de drenagem de Itaipú se observa nos últimos anos um aumento de vazão. E esse aumento é pobremente explicado por mudança de precipitação, e principalmente por mudança de uso do solo. Essencialmente a substituição de mata nativa (floresta) ou café, por pastagens.

Quando se procura o elo entre hidrologia/água e mudanças climáticas, é preciso ter atenção para não atribuir às mudanças climáticas certos efeitos que, na realidade, são devidos a mudanças no uso do solo.

Após discutir a temperatura e a precipitação, há necessidade de olhar mais amplamente para a modelagem da circulação atmosférica que prevê as mudanças climáticas. Eu acho que há um grande desafio científico nessa modelagem. De um ponto de vista hidrológico, é cientificamente mal definido.

J.P.C.: As relações entre as mudanças climáticas e a questão hídrica são projeções, cenários. Todos os melhores estudos revelam essa conexão, principalmente nas projeções e verificação de impactos do que chamamos de "agravamento de eventos climáticos extremos", que são secas mais severas e prolongadas, chuvas mais intensas e concentradas.

Estes dois elementos, secas prolongadas e chuvas mais intensas, são elementos extremamente complicadores da gestão hídrica. Porque, do ponto de vista da gestão, o que se espera e o ideal para criar uma ambiente mais amigável de maior facilidade na gestão, são períodos de estiagem menos intensos e bem distribuídos, mas principalmente chuvas mais bem distribuídas.

Assim, por um lado, se a gestão dos recursos hídricos se torna cada vez mais complexa, os reservatórios são ameaçados com uma capacidade de armazenamento reduzida. Por outro lado, o excesso de água também tem complicado as condições de manutenção dos reservatórios. Além de todos os problemas de assoreamento 
causados por chuvas fortes devido ao desmatamento na região dos mananciais. Então, é um agravante.

Uma situação que hoje já é dramática no Brasil é a boa gestão dos recursos hídricos. Já não há boa gestão num ambiente digamos "normal", e esta se tornará ainda mais desafiadora num contexto de agravamento das mudanças climáticas. E independentemente do grau de ocorrência ou não desses eventos extremos, o fato é que as políticas públicas não incorporam esses cenários. Na verdade, não apenas na gestão da água, as políticas públicas não integram o agravamento das mudanças climáticas em nenhuma área da gestão pública no Brasil. Todas as medidas de mitigação e adaptação estão extremamente atrasadas quando comparadas com países que já estão no processo de replanejamento dos seus sistemas de abastecimento de água para os próximos 20 ou 30 anos. A realidade é que nós não estamos preparados.

L.K., G.B.: Há poucos anos grandes centros urbanos como São Paulo e Brasília passaram por crises hídricas significativas. Quais foram as principais causas dessas crises? Quais os principais aprendizados?

J.K.: Vou falar mais especificamente sobre o caso de São Paulo, porque vivi de perto aquela situação. Na verdade, assumi o meu posto na Sabesp [empresa de saneamento básico do Estado de São Paulo] quando o estoque de água nos reservatórios era suficiente para cerca de um mês, havia cerca de $3 \%$ de água reservada. Fui convidado a preparar a empresa para uma calamidade, que seria o colapso total do fornecimento para 20 milhões de habitantes. A preparação para este desastre significou realizar obras para garantir o abastecimento ininterrupto de água a grandes hospitais, grandes centros penitenciários e grandes centros de hemodiálise.

o que causou aquela situação? Uma seca excepcional. Ao projetar o sistema de abastecimento de água, os hidrólogos usam séries históricas de fluxo ou previsões probabilísticas. Você usa a série de fluxo histórico quando é longo o suficiente, e São Paulo tinha um sistema projetado para lidar com a pior seca dos últimos 90 anos. Assim, o que aconteceu em 2014-2015 foi uma seca extraordinariamente rara, deixando a reserva com metade da taxa da pior seca dos últimos 90 anos e um quarto da vazão média afluente anual. Poucos sistemas de abastecimento de água no mundo estariam preparados para esta eventualidade. E São Paulo não estava, a Sabesp tampouco.

O que foi necessário fazer foi uma série de obras extraordinárias e emergenciais para conectar os sistemas produtores de água, tanto na forma de água bruta, que eram canais para levar água bruta de uma fonte para outra, como na rede de água potável que interligava as redes de distribuição. Foi feito também um sistema de controle de pressão. $\mathrm{O}$ consumo da população diminuiu voluntariamente, também através de incentivos econômicos ao consumidor, com um desconto para quem poupou e uma penalização para quem consumiu mais.

A combinação destas três medidas, os trabalhos de interligação, o controle da pressão sobre a rede e os incentivos econômicos para os usuários, nos permitiu superar a crise sem a ocorrência da tão temida calamidade.

Qual foi a atitude da Sabesp em relação ao planejamento após este evento? A posição da empresa foi que se aconteceu uma vez, poderia acontecer novamente. No mínimo, temos de estar preparados para a repetição deste fenômeno, que parecia raro, mas que agora devemos considerar possível. Para isso, foi necessário realizar grandes 
obras de infra-estrutura. E como o problema da qualidade da água está ligado ao problema da quantidade, as fontes existentes na Região Metropolitana de São Paulo (RMSP) já estavam exauridas, seja porque onde ela pode ser usada, ela já está sendo, ou porque a qualidade da água é tão ruim, por conta da coleta e do tratamento de águas residuais, que ela não pode ser usada. Assim, a solução foi trazer a água de longe, de fontes de muito boa qualidade situadas a $.80 \mathrm{~km}$ da RMSP Hoje, São Paulo tem esse reforço e acho que o fornecimento está assegurado.

J.P.C.: A crise da água em São Paulo de 2014 a 2016 é bem explicada pela meteorologia. Havia uma relação direta com a formação de uma barreira que impedia a chegada da chuva, devido ao fenômeno dos rios voadores. As chuvas, que vêm da região amazônica, colidem nos Andes e vão em direção à região sul/sudeste do Brasil, Argentina, Uruguai e Paraguai. Formou-se uma barreira que impediu a chegada destas nuvens carregadas de água e isso causou uma interrupção das chuvas nesta região, agravando o problema da seca em toda a região sudeste, mas especialmente em São Paulo, onde a crise foi muito intensa.

Em relação às lições aprendidas, é importante destacar a fragilidade que uma megal ópole como São Paulo tem em relação aos fenômenos meteorológicos, que não estão sob nosso controle.

O primeiro fator chave é a questão do uso da água. A população de São Paulo está preparada para este tipo de situação? Eles estão cientes desta situação? Acho que não estão. Não existe um sistema de informação que permita que a população tenha perspectiva e seja informada. Pelo contrário, o público, o cidadão, é tratado apenas como um consumidor. Se você não tem uma população envolvida, se a população não está mobilizada para buscar alternativas e colaborar para além de uma ação moment ânea de redução do consumo, para economizar, você não tem o parceiro principal que é a sociedade.

Mas nós não tivemos isso durante a crise, pelo contrário. A população foi mobilizada. Este sistema, que começou em 2014/2015 e que deveria ter sido um ganho permanente para a gestão da água, foi inicialmente abandonado assim que as chuvas voltaram. Todas as políticas que estimularam a redução e fizeram as famílias investirem em sistemas alternativos de captação, utilizando os bônus que receberam na redução da conta, todos estes incentivos ao consumo consciente foram cancelados sem qualquer consulta. Por isso, foi algo bastante demobilizador.

Hoje, o aumento do consumo é incentivado porque toda a geração de recursos para garantir o equilíbrio financeiro do prestador de serviços, neste caso a Sabesp, depende do volume de água vendida. Esta lição não foi, portanto, aprendida.

Em segundo lugar, há a questão da necessidade de se assegurar que as fontes de água sejam devidamente protegidas A crise demonstrou a necessidade vital que temos de não poluir os mananciais mais próximas das regiões de consumo

As autoridades públicas deveriam, portanto, ter reconhecido a importância de implementar políticas públicas mais intensivas para a conservação e proteção dos mananciais. Entretanto, isso não aconteceu. Pelo contrário, todos os investimentos foram e continuam a ser feitos para garantir a oferta.

O cidadão paulistano não incorporou de forma permanentemente uma postura de uso mais racional e econômico da água. Foi sazonal. As fontes de água estão se 
degradando a um ritmo acelerado, e isso não mudou. Então, as lições não foram aprendidas.

L.K., G.B. : Quais são os principais gargalos para o uso sustentável da água na agricultura?

J.K.: O principal mecanismo à disposição do governo para assegurar um uso mais eficiente da água é o sistema de outorga. A eficácia deste sistema envolve um equilíbrio entre a demanda e a disponibilidade de água. Portanto, significa ter uma rede de informações hidrológicas que lhe permita estimar com alguma precisão a vazão dos rios, as distribuições de probabilidade e a quantidade de água que pode alocar para o uso produtivo com uma certa confiabilidade. Isso é hidrologia, é conhecimento sobre a natureza e a Agência Nacional de Águas (ANA) tem-no muito bem. A Agência possui uma rede de informação hidrológica extensa e de boa qualidade.

Portanto, acho que devíamos ter um sistema centralizado para gerir a outorga. Não é razoável cotinuar o que se faz hoje, ou seja, que em alguns rios da mesma bacia, entidades diferentes possam conceder outorgas sem avaliar globalmente o que já foi concedido, sem considerar a disponibilidade total da bacia. A implementação de um sistema unificado por bacia hidrográfica ainda não está concluída e, se eu estivesse na ANA, este seria o principal tópico em que eu estaria trabalhando.

J.P.C.: Na verdade, é um misto disso. Outorga é central. o processo de outorga deveria levar em consideração não apenas o volume de água disponível, mas também a distribuição desse volume entre os diferentes atores que o utilizam. Basicamente, a atribuição é baseada no volume de água disponível e na procura e, portanto, uma distribuição desta procura tendo em conta as prioridades legais. Mas isto é um equívoco. Porque a outorga deveria também vincular essa questão do acesso à garantia de produção de água.

Neste sentido, poderíamos dizer que a água está sendo usada no seu limite e assim, compromete as condições ambientais necessárias - não apenas para uso humano em várias frentes: agricultura, indústria, saneamento público, bem-estar animal, etc. mas também para o meio ambiente. A água também é necessária para a manutenção das funções ecológicas, dos ecossistemas, que também são responsáveis pela qualidade da própria água. É um ciclo fechado.

A questão do uso da água na agricultura é um grande problema porque pressupõe e se baseia em uma intensificação da produção agrícola. Esta última é desejável, porque se você aumenta a produtividade, você minimiza a necessidade de expansão de área. Quanto menos expansão de área for necessária, mais ambientes naturais podem ser preservados, embora esta equação não seja tão simples. O problema é que a intensificação leva à intensificação e à expansão intensificada da agricultura. Então basicamente o que estamos vendo é um crescimento extremamente acelerado na irrigação. Porque a intensificação está crescendo cada vez mais. E esta intensificação do uso da irrigação compromete a disponibilidade de água. $\mathrm{O}$ sistema mais racional e econômico com menos perda de água, que é a irrigação por gotejamento por exemplo, é um sistema menos utilizado porque é mais caro e mais complexo.

Aí entra também o problema do pagamento. Essas outorgas e o valor pago pelo acesso a esta água é irrisório. É um custo secundário, não um custo efetivo. Se eu não tenho a responsabilidade de preservar as fontes das quais retiro água, e também pago uma quantia irrisória pela água que retiro, então claramente eu não tenho nenhum 
incentivo para racionar o consumo. E isto é o que acontece em grandes propriedades rurais. Não há nenhum custo para usar essa água..

Então, a agricultura, cada vez mais se torna, do ponto de vista dos recursos hídricos, um fator de degradação pelo excesso do uso da água. Fora a questão da contaminação por agrotóxicos, a questão do assoreamento devido más práticas agrícolas de controle de erosão.

L.K., G.B.: Qual seria a prioridade número um para promover a segurança da água no Brasil?

J.K.: A implantação, na escala da bacia hidrográfica, de um sistema de outorga e cobrança pelo uso de recursos hídricos.

J.P.C.: Esse é um sistema que interliga um conjunto enorme de ações e de frentes. Sob o ponto de vista da justiça social, o número um seria a universalização do abastecimento. Mas sob que condições e com que riscos? Universalização da oferta com tratamento efetivo? Não há solução para a questão hídrica que envolva uma única medida, uma bala de prata ou uma medida miraculosa. É necessário formular um plano de ação bem estruturado que possa identificar as diferentes frentes que requerem medidas concretas. Um plano de ação integrado, uma valorização do cidadão que deve deixar de ser consumidor. As pessoas precisam parar de achar que a água nasce na torneira e agir de forma mais responsável. Não há solução a curto prazo, não há solução milagrosa. A prioridade é a segurança hídrica.

Precisamos estabelecer a "nova cultura da água", ou seja, uma nova cultura de proteção da água. A água é um bem finito, extremamente limitado, muito mais limitado do que as pessoas pensam. É necessário mudar a forma como pensamos sobre isso, a forma como olhamos para ele. Esta é a nossa maior luta contra o grupo que tem uma visão mais tecnocrática do uso da água, da questão da gestão da água.

\section{BIBLIOGRAFIA}

Talvez, se você insistir em uma única medida, seria uma obrigação para todos mudar sua percepção da gestão da água, integrando a sustentabilidade e o uso de sistemas naturais menos intensivos no tratamento e distribuição da água, chamada de "rede inteligente".

Agência Nacional De Águas (ANA). Relatório Conjuntura dos Recursos Hídricos, 2019. http:// conjuntura.ana.gov.br, acesso efectuado em 6/03/2020

Civil society working group for the 2030 agenda (CSWG2030). Spotlight Report the 2030 Sustainable Development Agenda: Synthesis III Brazil. https://brasilnaagenda2030.files.wordpress.com/2019/09/ relatorio_luz_ingles_final_v2_download.pdf, acesso efectuado em 6/03/2020

Rajendra K., Pachauri, Meyer, Leo, et al., Intergovernmental Panel On Climate Change (IPCC). Climate Change 2014: Synthesis Report, Genebra, 2014. https://www.ipcc.ch/site/assets/uploads/ 2018/02/SYR_AR5_FINAL_full.pdf, acesso efectuado em 6/03/2020 
Intergovernmental Panel On Climate Change (IPCC). Global Warming of $1.5^{\circ} \mathrm{C}$. An IPCC Special Report on the impacts of global warming of $1.5^{\circ} \mathrm{C}$ above pre-industrial levels and related global greenhouse gas emission pathways, in the context of strengthening the global response to the threat of climate change, sustainable development, and efforts to eradicate poverty, 2018. https://www.ipcc.ch/sr15/, acesso efectuado em 6/03/2020

Marengo, José Antonio. «Água e mudanças climáticas ». Revista de Estudos Avançados, vol. 22, n63, 2008. http://www.periodicos.usp.br/eav/article/view/10294, acesso efectuado em 6/03/2020

Un-Water. Water Security \& the Global Water Agenda, 2013. https://www.unwater.org/publications/ water-security-global-water-agenda/, acesso efectuado em 6/03/2020

World economic forum (WEF). The Global Risks Report (15 ${ }^{\text {th }}$ Edition), 2020. http://

www3.weforum.org/docs/WEF_Global_Risks_Report_2019.pdf, acesso efectuado em 6/03/2020

\section{AUTORES}

\section{LIVIA KALIL}

Doutoranda contratual em Ciências Políticas, IHEAL (CREDA UMR 7227), Universidade Sorbonne Nouvelle - Paris 3 em cotutela no Programa de Pós-Graduação em Ciências Ambientais (PROCAM) da Universidade de São Paulo (USP). Coordenadora do Polo Brasil do Instituto das Américas. liviamaria.kalil@gmail.com

\section{GUILHERME B. CHECCO}

Doutorando em Mudança Social e Participação Política na Escola de Artes e Ciências da Universidade de São Paulo (EACH/USP) e Mestre em Ciência Ambiental pelo Instituto de Energia e Ambiente (IEE/USP). Pesquisador e Coordenador de projetos do Instituto Democracia e Sustentabilidade (IDS). guichecco@hotmail.com 